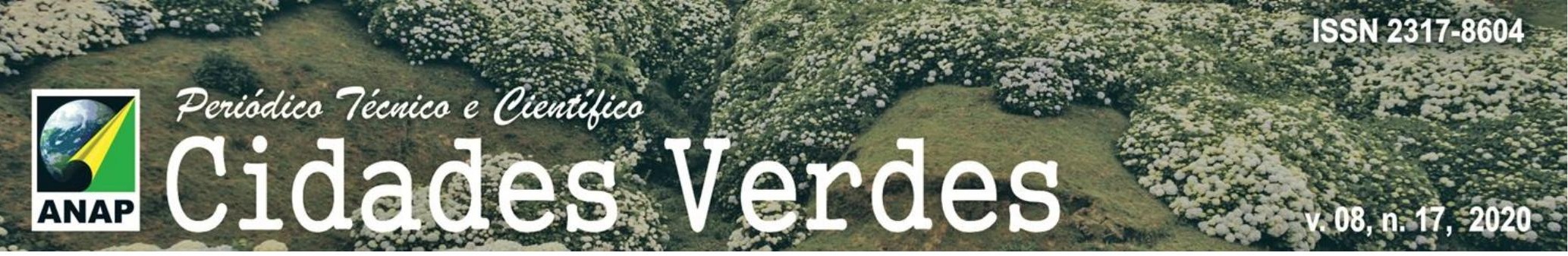

\title{
Análise Comparativa entre a Fotocatálise Heterogênea e a Eletrofloculação para o Tratamento de Efluentes de Celulose e Papel
}

Comparative Analysis between Heterogeneous Photocatalysis and Electroflocculation for the Treatment of Pulp and Paper Effluents

Análisis comparativo entre fotocatálisis heterogénea y electrofloculación para el tratamiento de efluentes de pulpa y papel

Marco Antonio Cardoso de Souza Doutorando em Engenharia e Ciências de Materiais, UEPG, Brasil marko.cardoso@hotmail.com

Erickson Alex de Lima Mestrando em Engenharia Ambiental, UTFPR, Brasil. erickson.lima@outlook.com

Isaias do Espírito Santo Tavera Acadêmico de Engenharia de Produção, FATEB, Brasil. isaiastavera@hotmai.com 


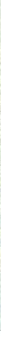

\title{
RESUMO
}

Com o passar das últimas décadas pode-se observar que o meio ambiente principalmente os meios hídricos foram constantemente poluídos pelo homem devido ao elevado grau de desenvolvimento industrial e ao despejo inadequado de resíduos gerados por esses processos em meios hídricos. Entretanto atualmente as indústrias buscam cada vez mais pela utilização e pesquisa de novas tecnologias que possibilitem a realização de um tratamento adequado para com os seus resíduos como os efluentes industriais antes de descartar os mesmos. O presente artigo tem como objetivo comparar e analisar a aplicação do processo eletroquímico de eletrofloculação com dois tipos distintos de eletrodos (ferro e alumínio) para com o processo oxidativo avançado da fotocatálise heterogênea utilizando como catalisadores dióxido de titânio, pentóxido de nióbio e óxido de zinco para promover a redução de parâmetros físico-químicos de coloração, demanda química de oxigênio, turbidez e pH. Através dos resultados obtidos pode-se constatar que ambos os processos se mostraram eficientes, mas a eletrofloculação apresentou os melhores resultados para redução de DQO e coloração com eficiência de $71 \% 78 \%$ respectivamente com o eletrodo de alumínio e para os processos fotocatalíticos os melhores resultados foram obtidos para com o dióxido de titânio com um eficiência de remoção de DQO e coloração de 66\% e 69\% respectivamente.

PALAVRAS-CHAVE: Eletrofloculação. Fotocatálise Heterogênea. Efluentes Industriais.

\begin{abstract}
Over the last few decades, It can be seen that the environment, especially the water resources, has been contaminated by humans due to the level of industrial development and the disposal of waste generated by these processes in water. Nowadays, companies are increasingly looking for, using and researching new technologies, that allow the proper treatment of their residues as industrial effluents before discarding them. This article aims to compare and analyze an electrochemical electrofloculation process application with two types of electrodes (iron and aluminum) for the advanced oxidative process of heterogeneous photocatalysis using titanium dioxide, niobium pentoxide and zinc oxide catalysts to promote the reduction of physical and chemical parameters of coloration, chemical oxygen demand, turbidity and $\mathrm{pH}$. From the obtained results, it can be seen that both processes are most efficient, but the electrofloculation shows the best results for COD reduction and coloration with $71 \%$ efficiency and $78 \%$ respectively with the aluminum electrode and photocatalytic processes. were selected for titanium dioxide with COD removal efficiency $66 \%$ and $69 \%$ coloration, respectively.
\end{abstract}

KEYWORDS: Electrofloculation. Heterogeneous photocatalysis. Industrial Effluents.

\section{RESUMEN}

En las últimas décadas se puede mirar que el medio ambiente, especialmente el agua, ha sido constantemente contaminado por los humanos debido al alto grado de desarrollo industrial y la eliminación inadecuada de los resíduos generados por estos procesos en el agua. Sin embargo, hoy en día, las industrias buscan cada vez más el uso y la investigación de nuevas tecnologías que permitan el tratamiento adecuado de sus desechos como los efluentes industriales antes de desecharlos. El presente artículo tiene como objetivo comparar y analizar la aplicación del proceso de electrofloculación electroquímica con dos tipos distintos de electrodos (hierro y aluminio) al proceso oxidativo avanzado de la fotocatálisis heterogénea utilizando dióxido de titanio, pentóxido de niobio y óxido de zinc como catalizadores. para promover la reducción de los parámetros físico-químicos de tinción, demanda química de oxígeno, turbidez y $\mathrm{pH}$. De los resultados obtenidos se puede ver que ambos los procesos fueron eficientes, pero la electrofloculación presentó los mejores resultados para la reducción de DQO y la tinción con eficiência de $71 \%$ y $78 \%$ respectivamente con el electrodo de aluminio y para los procesos fotocatalíticos los mejores resultados se obtuvieron para el dióxido de titanio con una eficiencia de reducción de DQO y tinción de 66\% y 69\% respectivamente.

PALABRAS CLAVE: Electrofloculación. Fotocatálisis heterogénea. Efluentes industriales. 


\section{INTRODUÇÃO}

Uma das principais causas de preocupações que existem tanto para as pequenas como as grandes indústrias nos dias atuais consiste na realização de um despejo adequado para com os resíduos gerados pelas mesmas nos seus processos produtivos.

Para tanto cada vez mais pode ser observado nos dias atuais que as mesmas investem em novas pesquisas e descobrimento de novas tecnologias buscando promover um tratamento para os efluentes indústrias gerados de uma maneira mais eficaz, antes de realizar um descarte destes efluentes em meios hídricos, satisfazendo assim as normas do CONAMA (2011).

Desta forma é de suma importância realizar pesquisas com técnicas que possibilitem uma ótima redução de parâmetros dos efluentes industriais como por exemplo para os parâmetros de demanda química de oxigênio, coloração, ph, turbidez.

Algumas das principais alternativas para tanto consiste na utilização de processos oxidativos avançados como a fotocatálise heterogênea ou ainda na aplicação de processos eletroquímicos como a eletrofloculação e eletrodecantação em sua maioria devido ao elevado grau de eficiência demonstrado através da aplicação destes processos.

\subsection{Processo de Fabricação de Celulose e Papel}

De acordo com SOUZA (2014) nos decorrer dos dias atuais a principal técnica utilizada para a produção de papel e celulose consiste no processo de polpação alcalina Kraft conforme demonstrado na Figura 1.

Figura 1 - Processo de fabricação de celulose e papel (Kraft)

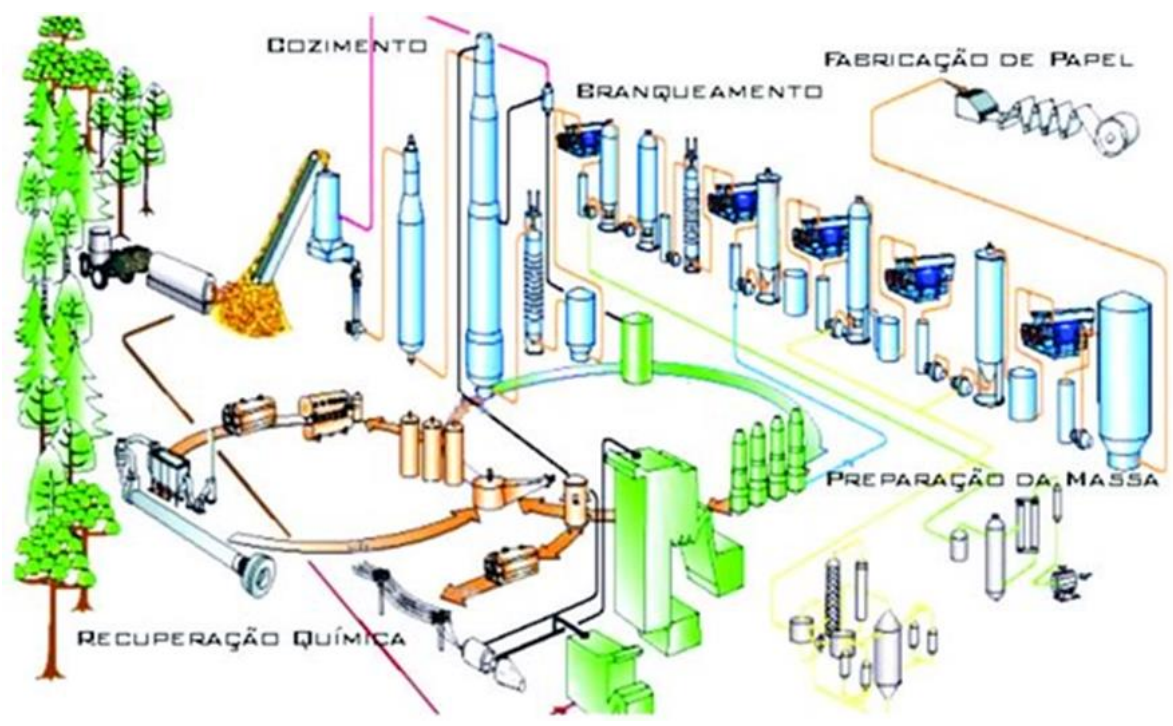

Fonte: SOUZA (2014)

O processo de polpação Kraft foi desenvolvido por Dahl no decorrer do ano de 1879 (FAVARO, 2015). 
No decorrer do processo de ocorre a fabricação de polpa celulósica utiliza-se um processo de polpação alcalina aonde se impregna em cavacos de madeira um composto constituído de soda caustica como licor de cozimento objetivando proporcionar uma maior separação das cadeias de celulose (Figura 2) existente na estrutura da madeira dos demais componentes existentes na mesma (SOUZA, 2014).

Figura 2 - Estrutura da celulose

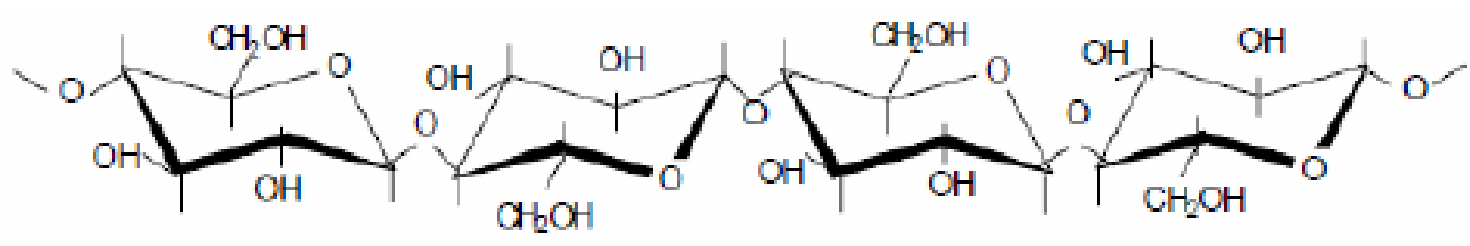

Fonte: Klock, (2005, p. 45).

Após realizar a extração da celulose a mesma segue para as demais etapas do processo produtivo gerando por sua vez uma maior quantidade de efluente industrial como na etapa de branqueamento aonde ocorre a adição de produtos químicos com a finalidade de remover a coloração da polpa celulósica (SOUZA, 2019).

Devido a elevada aplicação de produtos químicos para a remoção da lignina no decorrer da etapa de branqueamento no processos Kraft esta etapa pode ser considerada como a maior provedora da geração de efluentes líquidos neste processo produtivo (MATIAS, 2010).

MATIAS (2010) constata que devido ao elevado teor de compostos orgânicos no efluente de celulose e papel provenientes dos mais variados tipos de componentes da madeira bem como dos produtos químicos empregados no processo produtivo o mesmo apresenta um elevado valores para o parâmetro da demanda química de oxigênio.

Para tanto é de suma importância a realização de tratamento dos efluentes industriais bem como pesquisas que desenvolvam técnicas que tornem os tratamentos mais eficientes e menos dispendiosos.

\subsection{Efluente industrial}

De acordo com BEUX (2005) devido à elevada variação sofrida pelos parâmetros característicos dos efluentes industriais em sua maioria devido aos métodos produtivos utilizados nas indústrias cada indústria deve realizar uma análise e determinar processos para a realização do tratamento de seus resíduos gerados.

Para a realização do presente artigo inicialmente realizou-se a coleta de uma amostra de efluente industrial de celulose e papel proveniente de uma determinada indústria e em seguida realizou-se um processo de filtragem e determinação das principais propriedades de coloração, demanda química de oxigênio, turbidez, pH do mesmo objetivando realizar uma comparação para com os valores obtidos após o tratamento do mesmo. 


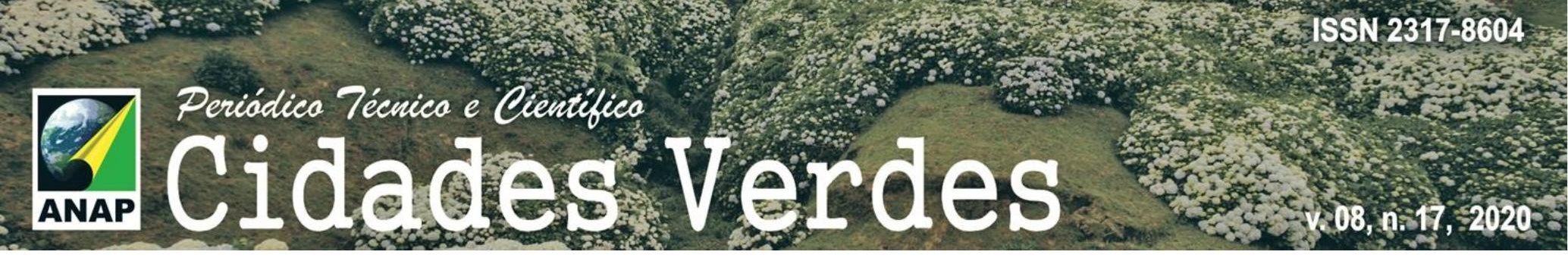

De acordo com o CONAMA (2011) a realização de um tratamento prévio e adequado dos efluentes e resíduos industriais oriundos dos processos antes que os mesmos sejam descartados no meio ambiente consiste em um fator de elevado grau de importância.

\subsection{Tratamento de efluentes industriais}

Para BELTRAME, (2016) antes de se realizar um determinado tipo de tratamento em efluentes industriais torna-se necessário que se possua um conhecimento referente a natureza, bem como da origem e características físico-quimicas do mesmo

Hodiernamente graças ao elevado consumo de água em processos industriais e ao crescimento da mesma, trona-se de suma importância a realização de processos que promovam um tratamento adequado dos efluentes gerados pelas indústrias (COSTA, 2009).

NOGUEIRA (1997) afirma que um dos maiores problemas enfrentados nos dias atuais consiste em se combater a contaminação do meio ambiente.

Entretanto de acordo com NETO (2011) nos dias atuais existe uma grande variedade de processos que possibilitam a realização do tratamento de efluentes industriais proporcionando uma remoção de contaminantes orgânicos dissolvidos nos mesmos.

Os processos de tratamento de efluentes em sua maioria são divididos em 3 tipos distintos de acordo com SOUZA (2019) conforme demonstrado na Tabela 1.

Tabela 1 - Tratamento de efluentes industriais

\begin{tabular}{ccc}
\cline { 2 - 3 } & \multicolumn{3}{c}{ Tratamento de efluentes industriais } \\
\cline { 2 - 4 } Químicos & Processos Físicos & Processos Biológicos \\
\hline POA'S & Filtração & Aeróbio \\
Eletroquímicos & Decantação & Anaeróbio \\
\hline
\end{tabular}

Fonte: Elaborado pelos autores

Para promover melhores resultados no tratamento de efluentes de celulose e papel em sua maioria utiliza-se uma mistura dos processos existentes (MATIAS, 2010).

A utilização da eletrofloculação para o tratamento de efluentes industriais mostra-se eficiente para remover compostos orgânicos devido a floculação e/ou decantação destes materiais quando ocorre a passagem de uma corrente elétrica pelo efluente (GOBBI, 2013).

A aplicação de processos oxidativos avançados dentre eles o processo da fotocatálise heterogênea e o processo fenton mostram-se como alternativas viáveis para a aplicação em tratamento de efluentes industriais pois promovem uma remoção eficiente da matéria orgânica através da oxidação do meio como consiste no fato da fotocatálise heterogênea (NETO, 2011).

\subsection{Fotocatálise heterogênea}

O processo de fotocatálise heterogênea foi desenvolvido por volta de meados de 1970 através de pesquisas de Honda e Fujishima (1972). 
Nos dias atuais o processo de fotocatálise heterogênea vem sendo amplamente estudado e utilizado para promover a descontaminação de vários tipos de efluentes industriais (NOGUEIRA, 1997).

De acordo com NOGUEIRA (1997) no decorrer da aplicação do processo fotocatalítico ocorre inicialmente uma emissão de uma fonte luminosa (fóton) na superfície de um catalisador cerâmico aonde ocorre por sua vez um processo de interação entre elétrons emitidos para com os existentes na banda de valência deste catalisador cerâmico que está em contato com o efluente industrial,

O bombardeamento da superfície do catalisador com uma fonte luminosa proporciona o fornecimento uma energia de gap para o catalisador gerando desta forma um salto quântico energético dos elétrons presentes na banda de valência para a banda de condução originando assim a formação de um par elétron buraco (NOGUEIRA, 1997).

De acordo com MARQUES (2013) para que ocorra um processo fotocatalítico torna-se necessário a existência de fatores característicos como a existência de uma fonte luminosa, um catalisador com atributos de semicondutor e um efluente industrial que se pretende tratar através da presença de um meio oxidante.

Para FERREIRA (2004) para que o processo ocorra torna-se necessário que a energia que deve ser fornecida para o catalisador deve por sua vez ser equivalente ou superior a energia da banda de gap do catalisador utilizado, possibilitando desta maneira a ocorrência do salto quântico e oxidação do meio.

A Figura 3 demonstra como ocorre o processo de fotocatálise heterogênea.

Figura 3: Esquematização do processo de fotocatálise heterogênea

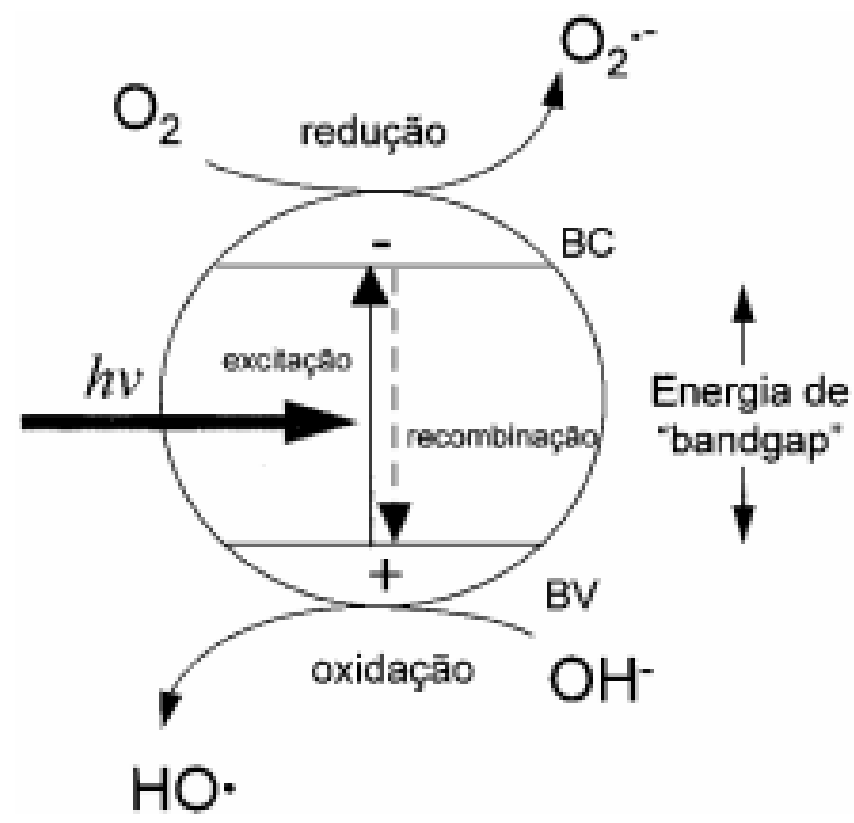

Fonte: Nogueira, 1997 
De acordo com BRITO (2012) após a aplicação da fotocatálise heterógena ocorre um processo de geração tanto de íons hidroxila $(\mathrm{OH}-)$ como de radicais hidroxila $(\mathrm{OH} \bullet)$ e estes por sua vez ocasionam os processos de degradação de componentes presentes nos efluentes industriais.

O processo de oxidação do efluente industrial ocorre porque este radical formado apresenta por sua vez um elevado grau de reatividade para processos de oxidação e assim acarretando na interação do mesmo para com a matéria orgânica do efluente industrial gerando uma reação de oxi-redução e então degradando a mesma, possibilitando um tratamento do efluente (SOSSMEIER, 2016).

\subsection{Catalisadores}

O conceito básico de um catalisador consiste em que o mesmo é um determinado material utilizado em um processo químico cujo qual não apresenta nenhuma relação para com os produtos gerados em uma reação química de acordo para com as relações estequiométricas do mesmo (CIOLA, 1981).

De acordo com CHIAVENATO (2017) uma vasta gama de catalisadores como óxido de zinco, dióxido de titânio, óxido de alumínio, óxido de ferro são utilizados em processos fotocatalíticos para promover o tratamento de efluentes industriais.

No decorrer do presente estudo para se realizar o processo de fotocatálise heterogênea foram utilizados os catalisadores cerâmicos de dióxido de titânio (P25), pentóxido de nióbio e o óxido de zinco.

Um dos melhores catalisadores utilizados para promover os processos de fotocatálise heterogênea consiste no dióxido de titânio devido a sua baixa toxidade, fácil aplicação e propriedades fotocatalíticas (FELTRIN, 2012).

De acordo com MARQUES (2005) o dióxido de titânio apresente uma estrutura polimórfica podendo estar presente nas fases de anatase, rutilo e brookita conforme demonstrado na Figura 4 , entretanto as que mais são utilizadas em processos catalíticos consistem na anatase e o rutilo.

Figura 4 - Estruturas cristalinas do dióxido de titânio

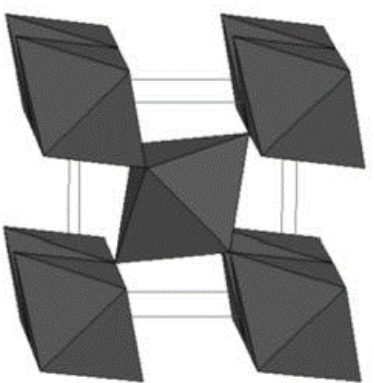

Rutilo

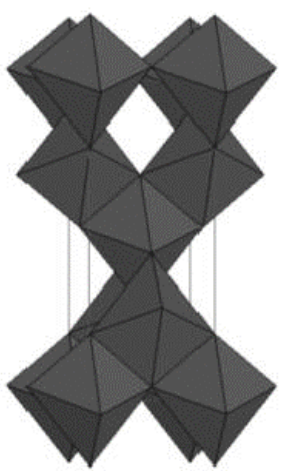

Anatase

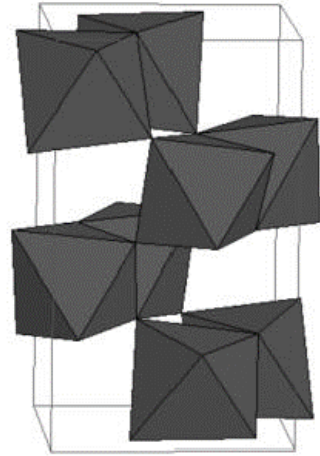

Brookita

Fonte: SOUZA (2019) 


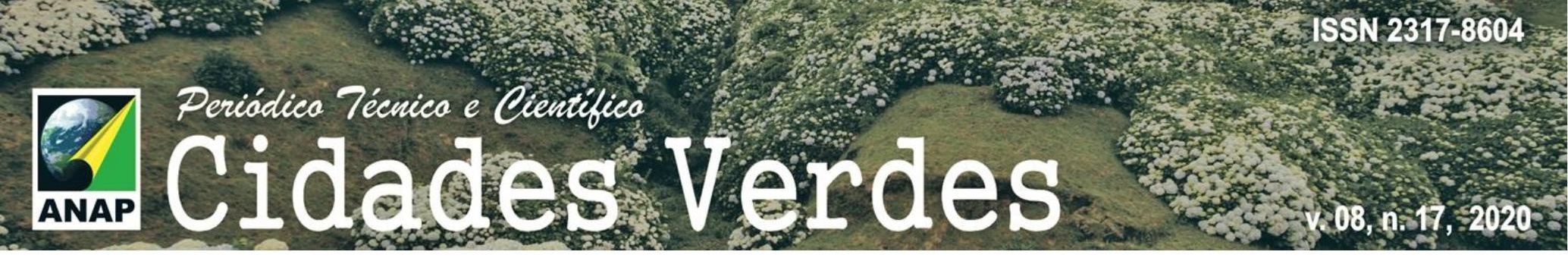

Uma das principais diferenças existentes entre as fases polimórficas do dióxido de titânio de anatase e rutilo consiste por sua vez na distância existe entre os átomos de titânio e oxigênio em sua estrutura cristalina (SOARES, 2013).

Ao longo das últimas décadas tem crescido a aplicação de produtos que possuam em sua estrutura o nióbio em vários setores industriais e para o desenvolvimento de novas tecnologias (LOPES, 2015).

De acordo com LOPES (2015) uma das aplicações do pentóxido de nióbio consiste na utilização do mesmo em processos fotocatalíticos devido as suas propriedades catalíticas.

DIAS (2014) constata que o óxido de zinco (ZnO) no decorrer dos últimos anos consiste em um catalisador cerâmico que pode ser aplicado de uma maneira ampla para a realização de processos de fotocatálise heterogênea devido a presença de propriedades fotoelétricas apresentas por este material quando o mesmo é exposto a radiação seja a mesma visível ou ultravioleta.

\subsection{Processos Eletroquímicos}

POON (1997) afirma que o processo de eletrofloculação é vastamente estudado para promover o tratamento de vários tipos de efluentes industriais e de água devido a grande simplicidade de aplicação desta técnica.

A aplicação do processo de eletrofloculação ou eletrocoagulação apresenta um elevado grau de eficiência quando utilizado para remover uma vasta gama de "poluentes" como a matéria orgânica (M.O) existentes em efluentes industriais como o de celulose e papel (CARVALHO, 2015).

EWERLING (2014) classifica o processo eletroquímico para o tratamento de efluentes industriais em quatro etapas conforme demonstrado na Tabela 2.

Tabela 2 - Etapas da eletrofloculação

\begin{tabular}{cl}
\hline Etapas & \multicolumn{1}{c}{ Descrição } \\
\hline Etapa 1 & Formação de bolhas no interior do efluente industrial \\
Etapa 2 & Interação entre as bolhas e compostos orgânicos em suspensão no efluente \\
Etapa 3 & Adsorção das bolhas de gás na superfície das partículas orgânicas \\
Etapa 4 & Floculação ou Decantação do conjunto partícula/bolha \\
\hline Fonte: Elaborado pelos autores
\end{tabular}

De acordo com FLECK (2013) o processo de eletroquímico para tratamento de efluentes tem como finalidade promover a aglomeração de partículas da matéria orgânica do efluente industrial quando ocorra uma aplicação de uma corrente elétrica no mesmo.

Para BELAN (2014) conforme ocorre a passagem de uma determinada corrente elétrica no efluente industrial através da utilização de eletrodos ocorre a formação de íons metálicos oriundos da decomposição dos eletrodos no meio aquoso promovendo desta maneira uma reação de oxi-redução de compostos orgânicos (Figura 5) e assim através da geração de bolhas de ar promover um processo de floculação ou decantação das partículas. 
Figura 5 - Geração de íons no processo eletroquímico

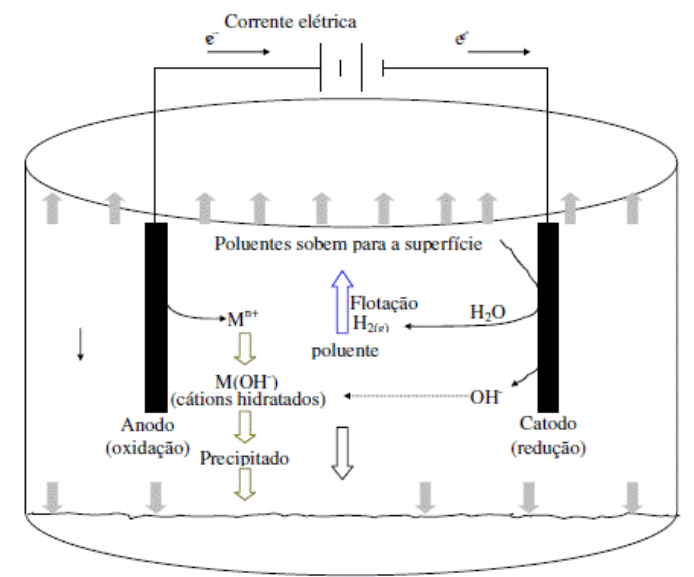

Fonte: MOLLAH (2008)

Para NASCIMENTO (2011) um dos principais fatores que pode influenciar a realização do processo de eletrofloculação para o tratamento de efluentes industriais ou água consiste na condutividade inicial apresentada pelo meio líquido que se pretende tratar.

\section{OBJETIVOS}

Analisar teoricamente através de pesquisas bibliográficas como ocorre os processos de fotocatálise heterogênea e eletroquímicos para tratamento de efluentes industriais.

Verificar qual dos processos utilizados demonstrou uma maior eficiência para a realização do tratamento de efluentes industriais.

Determinar a taxa de redução dos parâmetros físico químicos do efluente industrial relacionado ao $\mathrm{pH}$, condutividade, coloração e Demanda Química de Oxigênio do efluente durante o decorrer do tratamento.

\section{METODOLOGIA}

A metodologia utilizada no decorrer do presente estudo consiste em realizar um tratamento do efluente de uma indústria produtora de papel e celulose aplicando as técnicas de fotocatálise heterogênea e do processo eletroquímico de eletrofloculação para averiguar a eficiência da utilização destes processos para promover a redução de parâmetros de $\mathrm{pH}$, condutividade, coloração e Demanda Química de Oxigênio do efluente industrial.

Para a realização do processo de fotocatálise heterogênea aplicou-se 3 tipos distintos de catalizadores sendo os mesmos de pentóxido de nióbio $\left(\mathrm{Nb}_{2} \mathrm{O}_{5}\right)$, dióxido de titânio $\left(\mathrm{TiO}_{2}\right)$ e óxido de zinco $(\mathrm{ZnO})$. Já para a aplicação do processo de eletrofloculação aplicou-se dois tipos de eletrodos separadamente sendo os mesmos de alumínio (Al) e de ferro (Fe).

\section{RESULTADOS}


Para início da realização do processo obteve-se uma determinada amostra de efluente industrial que foi inicialmente filtrada utilizando papel filtro e determinado os parâmetros físico-químicos de $\mathrm{pH}$, condutividade, coloração e Demanda Química de Oxigênio e turbidez, para se realizar uma comparação destes valores para com os obtidos após o tratamento verificando desta forma a eficiência da aplicação dos mesmos.

Para a realização do tratamento eletroquímico realizou-se uma montagem de um reator eletroquímico utilizando para tanto eletrodos constituídos de barras de alumínio e de ferro, ligadas a fio condutores de eletricidade a uma fonte gerador de corrente elétrica e depositadas em um béquer de $1 \mathrm{~L}$ aonde foi colocado o efluente indústria para se iniciar o tratamento.

Para o processo de eletrofloculação se realizou uma comparação utilizando para tanto eletrodos metálicos compostos de alumínio e de ferro imersos em uma béquer contento o efluente industrial, e aplicando sobre estes eletrodos durante cerca de 30 minutos de reação uma corrente elétrica de aproximadamente $12 \mathrm{eV}$.

Os resultados da aplicação do processo eletroquímico são apresentados na Figura 6 aonde podese observar que para o parâmetro de redução da coloração a utilização do eletrodo de ferro se mostrou mais eficiente que o de alumínio com eficiências de $82 \%$ e $78 \%$ respectivamente, entretanto para a redução do parâmetro da demanda química de oxigênio observou-se que a maior eficiência se mostrou para o eletrodo de alumínio com eficiência de $71 \%$ e de para $66 \%$ com o eletrodo de ferro. Já para o parâmetro de análise referente a turbidez ambas apresentaram uma eficiência superior a $90 \%$.

Figura 6 - Redução dos parâmetros de coloração, DQO e turbidez após eletrofloculação
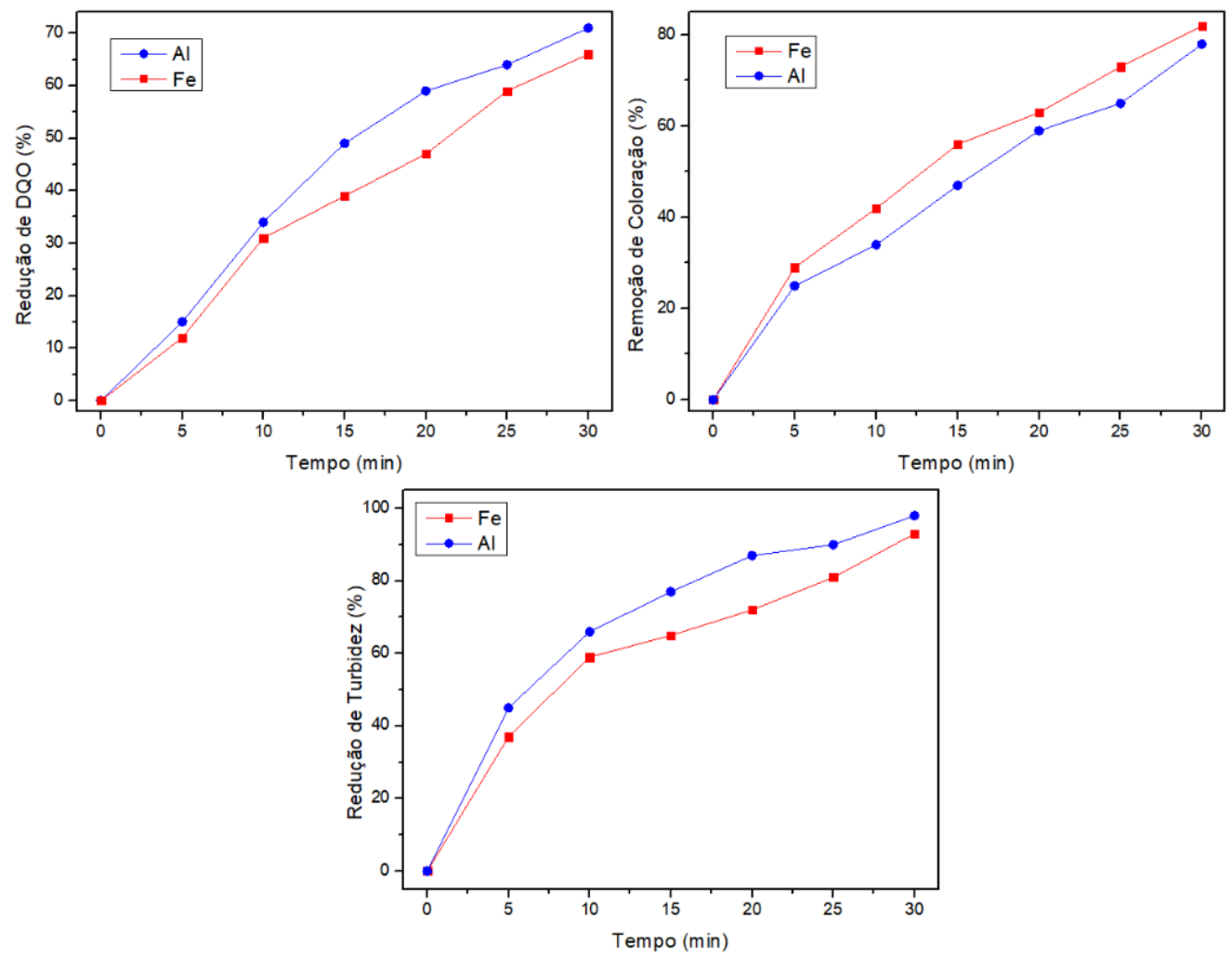

Fonte: Elaborado pelos autores 
Posteriormente se realizou uma análise referente a variação do $\mathrm{pH}$ da condutividade do efluente industrial de celulose e papel após a aplicação da eletrofloculação conforme demonstrado na Figura 7.

Figura 7 - Variação dos parâmetros de condutividade e pH
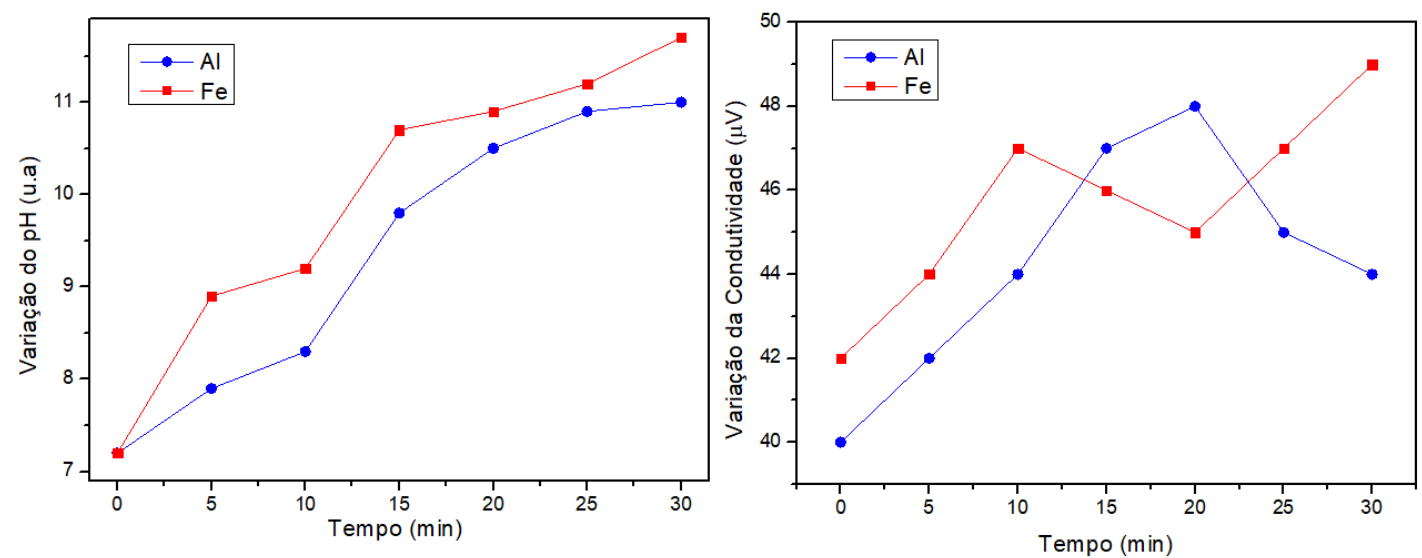

Fonte: Elaborado pelos autores

Pode-se constatar que a análise dos parâmetros de variação da condutividade permaneceu oscilando durante a realização do experimento para ambos os eletrodos analisados enquanto que ocorreu uma elevação do $\mathrm{pH}$ da amostra sendo o mesmo maior para o eletrodo de ferro do que para com o eletrodo de alumínio.

Para a realização do tratamento através do processo fotocatalítico montou-se um reator utilizando um copo de béquer de 1L, suporte universal, um fonte geradora de luz (ultravioleta ou visível), agitador, suporte universal e um gerador de bolhas de gás.

Para o processo de fotocatálise heterogênea aplicou-se como catalisadores os óxidos cerâmicos de pentóxido de nióbio, dióxido de titânio e de óxido de zinco.

No decorrer do processo fotocatalítico acrescentou-se em um béquer cerca de aproximadamente $1 \mathrm{~L}$ de efluente industrial utilizando uma relação para com o catalisador utilizado de $1 \mathrm{~g} / \mathrm{L}$. Posteriormente deixou-se essa amostra em agitação por 30 min para promover uma maior homogeneização do catalizador no meio e então ligou-se a lâmpada e se realizou o processo por 6 horas, e se coletou amostras para determinação dos parâmetros para determinar a eficiência do tratamento.

Os resultados obtidos para a aplicação do tratamento de fotocatálise heterogênea utilizando os catalisadores de pentóxido de nióbio, dióxido de titânio e de óxido de zinco para a remoção de coloração do efluente industrial e da demanda química de oxigênio estão apresentados na figura de 8 . 


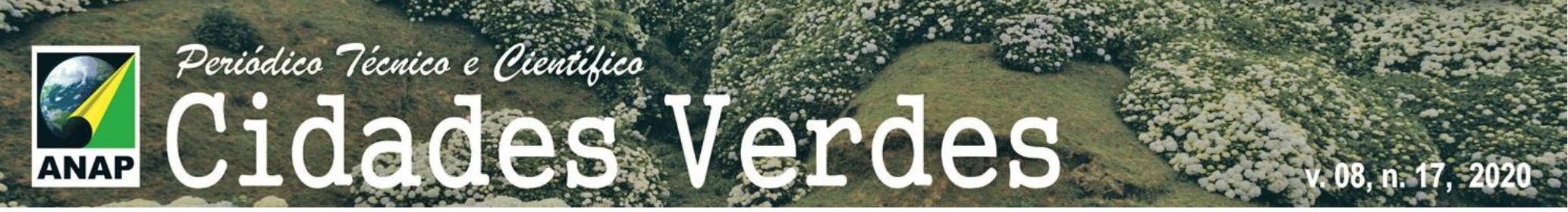

Figura 8 - Redução dos parâmetros de DQO, coloração e turbidez do efluente industrial após aplicação de fotocatálise heterogênea
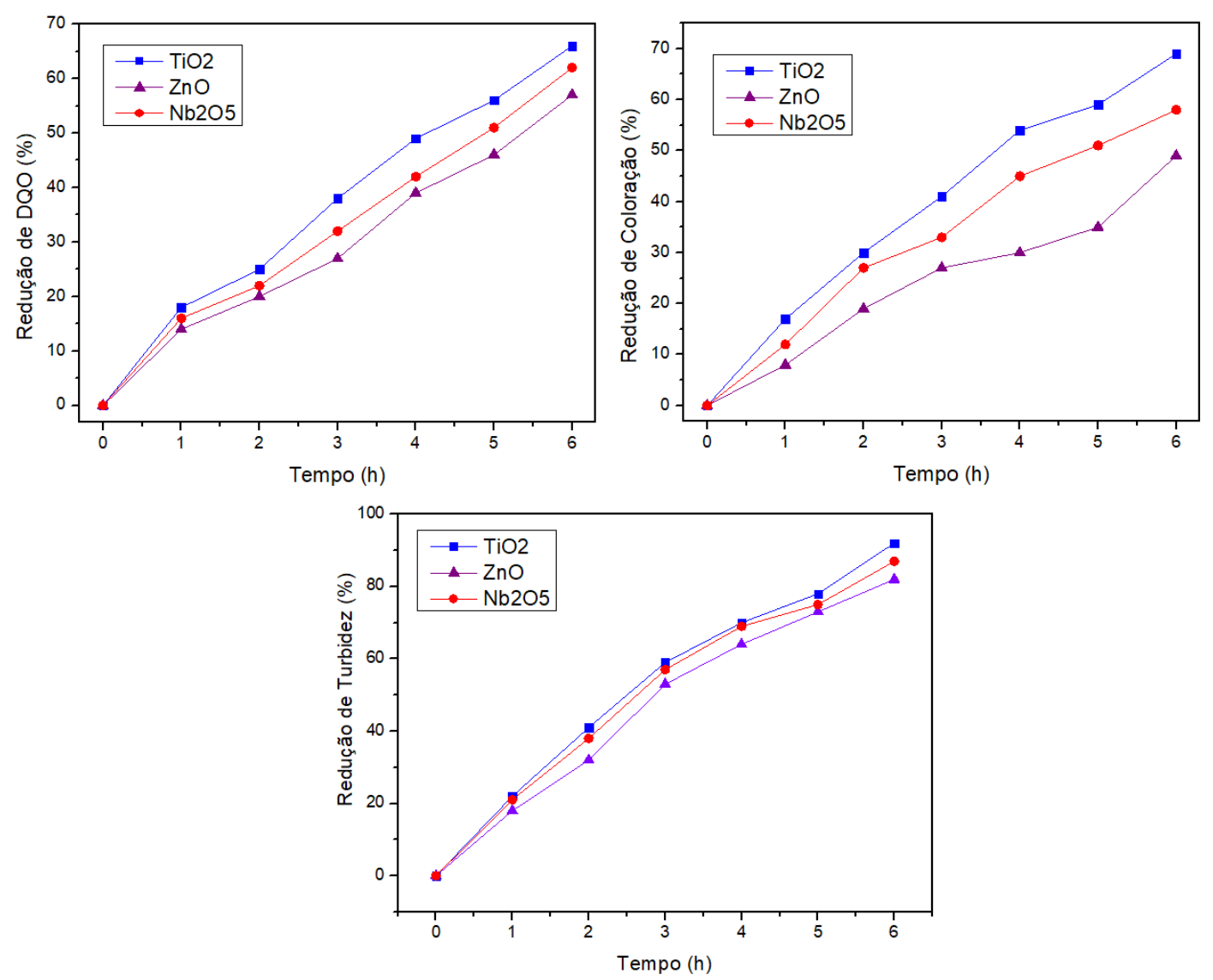

Fonte: Elaborado pelos autores

Com base nos resultados obtidos através do processo de tratamento do efluente utilizando a fotocatálise heterógena pode-se concluir que o catalisador de dióxido de titânio apresentou uma maior eficiência para a redução da coloração e da demanda química de oxigênio e para a redução da turbidez, com eficiência de 69\%,66\% e de 92\% respectivamente, seguido da amostra de pentóxido de nióbio com eficiência de $58 \%$ para coloração e $62 \%$ para demanda química de oxigênio e de $87 \%$ para turbidez , e o que apresentou a menor eficiência nesse caso foi o óxido de zinco com uma eficiência de $49 \%$ para cor e $57 \%$ para a demanda química de oxigênio e de aproximadamente $82 \%$ de turbidez.

Os resultados obtidos através da análise de $\mathrm{pH}$ das amostras de efluente industrial após a aplicação do processo de fotocatálise heterogênea estão demonstrados na Figura 9. 
Figura 9 - Variação do pH após fotocatálise

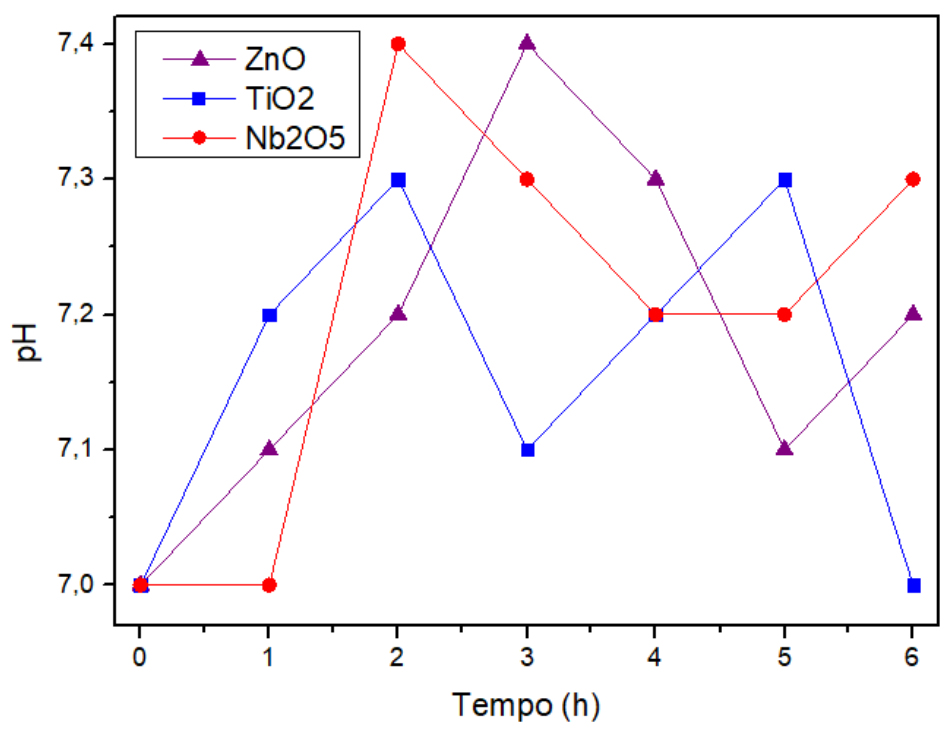

Fonte: Elaborado pelos autores

Conforme pode-se constatar através da análise do parâmetro de pH da amostras observa-se que o mesmo permanece variando entre valores próximos de 7 após a aplicação do tratamento do efluente industrial com ambas as amostras de catalisadores utilizadas no decorrer deste estudo.

\section{CONCLUSÃO}

Através dos resultados obtidos ao longo do presente estudo pode-se constatar que tanto a eficiência da aplicação do processo de fotocatálise heterogênea quanto de eletrofloculação mostrou-se eficaz para promover a redução dos parâmetros característicos deste efluente. A maior eficiência para a remoção da coloração se mostrou para a aplicação do processo de eletrofloculação com eficiência de $82 \%$ para o eletrodo de ferro e de $78 \%$ para o eletrodo de alumínio, para o processo fotocatalítico a maior eficiência foi observada para a aplicação do dióxido de titânio com $69 \%$ de remoção da coloração. O parâmetro de redução da turbidez obteve eficiência superior a $90 \%$ para todos os testes realizados. Em relação a demanda química de oxigênio a maior eficiência foi observada para com o eletrodo de alumínio com eficiência de $71 \%$ e para o catalisador de dióxido de titânio com $69 \%$ de eficiência.

\section{REFERÊNCIAS}

BELAN, ANDRÉ LUIZ DAMASCENO. Eletrofloculação aplicada ao tratamento de efluentes têxteis.

Trabalho de conclusão para obtenção de título de Especialista na Pós-Graduação em Gestão Ambiental, UTFPR, Medianeira, PR,2014

BELTRAME, THIAGO FAVARINI; ET.AL. Efluentes, resíduos sólidos e educação ambiental: uma discussão sobre o tema. Revista Eletrônica em Gestão, Educação e Tecnologia Ambiental, v. 20, n. 1, Santa Maria, Rio Grande do Sul, 2016. 


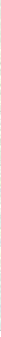

BERGER, J.S.; et.al. Relação entre série de sólidos e condutividade elétrica em biodigestor tubular utilizado no tratamento de efluente de amidonaria. Scientia Agraria Paranaensis - SAP, v.12, suplemento, dez., p.377-383, Marechal Cândido Rondon, Paraná, 2013.

BEUX, SIMONE. Avaliação do tratamento de efluente de abatedouro em digestores anaeróbios de duas fases. Dissertação de Mestrado em Ciência e Tecnologia de Alimentos pela UEPG, Ponta Grossa, Paraná.

BRITO, N. N. d. e SILVA, V. B. M. “Processo oxidativo avançado e sua aplicação ambiental”. REEC Revista Eletrônica de Engenharia Civil, vol. 1, no 3, pp. 36-47, 2012.

CARVALHO, D.L; SOUZA, M.A.C.; ZEMPULSKI, D.A. Utilização do método eletrofloculação para tratamento de efluentes industriais. Revista Nacional de Gerenciamento de Cidades, v. 03, n. 14, pp. 14-28, Tupã, São Paulo, 2015.

CETESB, COMPANHIA DE TECNOLOGIA DE SANEAMENTO AMBIENTAL. Guia técnico ambiental da industrial da papel e celulose -série p+l, Governo de São Paulo, São Paulo, 2008.

CHIAVENATO, F.F. Aplicação do processo de fotocatálise heterogênea para degradação do triclosan. Trabalho de Conclusão de Curso em Engenharia Química pela UTFPR, Ponta Grossa, Paraná, 2017.

CIOLA, R. "Fundamentos da catálise". 1 ed.,: MODERNA LTDA, São Paulo, São Paulo,1981, p. 377.

CONAMA - Conselho Nacional do Meio Ambiente. Resolução no 430, de 13 de maio de 2011. Dispõe sobre as condições e padrões de lançamento de efluentes, complementa e altera a Resolução no 357, de 17 de março de 2005, 2011, Brasil.

COSTA, ANA PAULA JAVAROTI; ET AL. Um estudo sobre estações de tratamento de efluentes industriais e sanitários da empresa Dori Alimentos LTDA. Revista de GraduaçãoUNIVEM v1, ano 2, pág 6-22. Marília São Paulo, 2009

CULLITY, B.D. Elements of X-ray diffraction. Massachusetts: Addison-Wesley, 1978.

DIAS, J. A; ET AL. Síntese e avaliação fotocatalítica de óxido de zinco nanoparticulado obtido por moagem de alta energia. 21을 CBECIMAT - Congresso Brasileiro de Engenharia e Ciência dos Materiais, Cuiabá, MT, 2014.

EWERLING, ALESSANDRO; at al. Eficiência do processo de eletrofloculação no tratamento do efluente de uma lavanderia industrial. Universidade Tecnológica Federal do Paraná, 2014

FAVARO, J.S.C. Estudos da polpação Kraft, branqueamento e refino de Eucalyptus gradis x Eucalyptus urophylla. Tese de doutorado em Engenharia Mecânica na área de Materiais Lignocelulósicos, pela Universidade Estadual Paulista, Guaratinguetá, São Paulo, p.180, 2015.

FELTRIN, J. "Estabilização a elevadas temperaturas da fase anatase com partículas submicrométricas de SiO2". Dissertação de Mestrado em Ciência e Engenharia dos Materiais pela Universidade Federal de Santa Catarina, Florianópolis, Santa Catarina, 2012, p. 109. 


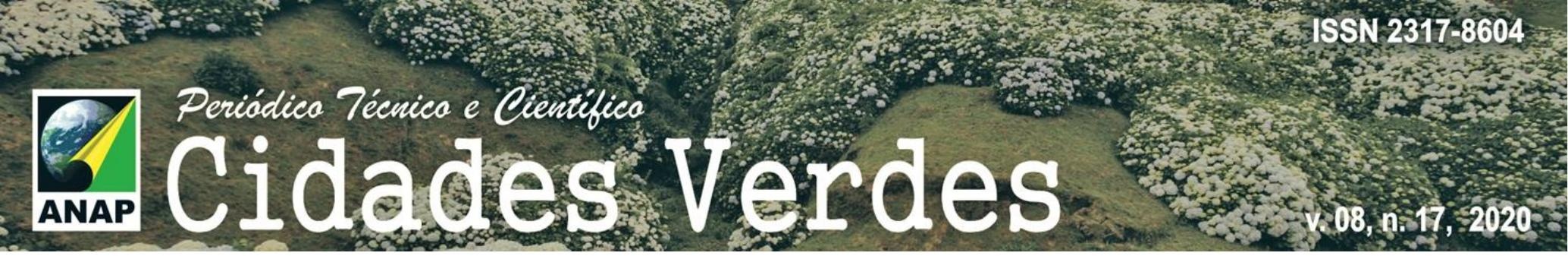

FERREIRA, I.V.L. Fotocatálise heterogênea com TiO2, aplicada ao tratamento de esgoto sanitário secundário. Revista Engenharia Sanitária e Ambiental Vol. 9 - № 4 - out/dez, p.335-342, Rio de Janeiro, 2004.

FLECK, LEANDRO et al. Utilização da técnica de eletrofloculação para o tratamento de efluentes têxteis: uma revisão. Revista EIXO, Brasília - DF, v.2 n.2, Julho - Dezembro de 2013.

FUJISHIMA, A.; HONDA, K. Eletrochemical photolysis of water at a semiconductor electrode. Nature, vol. 238, pp. 37-38, Julho, 1972

GOBBI, L.C.A. Tratamento de água oleosa por eletrofloculação. Dissertação de Mestrado em Energia pelo Centro Universitário Norte do Espírito Santo da Universidade Federal do Espírito Santo, São Mateus, ES, 2013

MARQUES, R. G. "Decomposição Fotocatalítica de Gasolina Sintética e Comercial". Dissertação de Mestrado em Engenharia Química, na área de desenvolvimento de processos pela Universidade Estadual de Maringa, UEM, Maringá, Paraná, 2005.

MARQUES, RUBIANE GANASCIM; SANATANA, VERONICE SLUSARKI; MACHADO, NÁDIA REGINA CAMARGO FERNANDES. Estudo da fotodegradação de efluente de indústria de celulose e papel empregando os fotocatalisadores de $\mathrm{TiO}_{2}, \mathrm{ZnO} \mathrm{E} \mathrm{Nb}_{2} \mathrm{O}_{5}$. Periódico eletrônico do alta paulista, Volume 9, Número 11, Tupã, 2013.

MATIAS, A. A. Tratamento de efluente de indústria de celulose através de plasma obtido por eletrólise de alta tensão. Dissertação de Mestrado em Agroquímica pela Universidade Federal de Viçosa, Viçosa, Minas Gerais, 2010, p. 79.

MOLLAH, M. Y. A.; GOMES, J. A.; DAS, K. K.; COCKE, D.L. Fundamentals, present and future perspectives of electrocoagulation, Journal of Hazardous Materials, v. 114, p. 199-210, 2004

NASCIMENTO, M.R do. Revisão: a sinergia das técnicas eletrofloculação-eletrocoagulação para a desestabilização de emulsões tipo óleo-água. Revista Principia, IFPB. João Pessoa, Dezembro, 2011.

NETO, SIDNEY DE AQUINO; et al. Tratamento de resíduos de corante por eletrofloculação: um experimento para cursos de graduação em química. Química Nova, vol 34. São Paulo, 2011

NOGUEIRA, RAQUEL F. P. ET AL. A fotocatálise heterogênea e sua aplicação ambiental. Revista Química Nova, Volume 21, n.1, p. 69-72, Campinas, SP, 1997.

POON, C. P. C., Electroflotation for groundwater decontamination. Journal of Hazardous Materials, v. 550, p. 159-170, 1997.

SOSSMEIER, T. R. Sintese caracterização e atividade fotocatalítica de dióxido de titânio dopado com óxido de cério. Dissertação de Mestrado em Engenharia Química pelo Programa de Pós-Graduação em Engenharia Química da Universidade Federal de Santa Catarina, Florianópolis, Santa Catarina, 2016. 


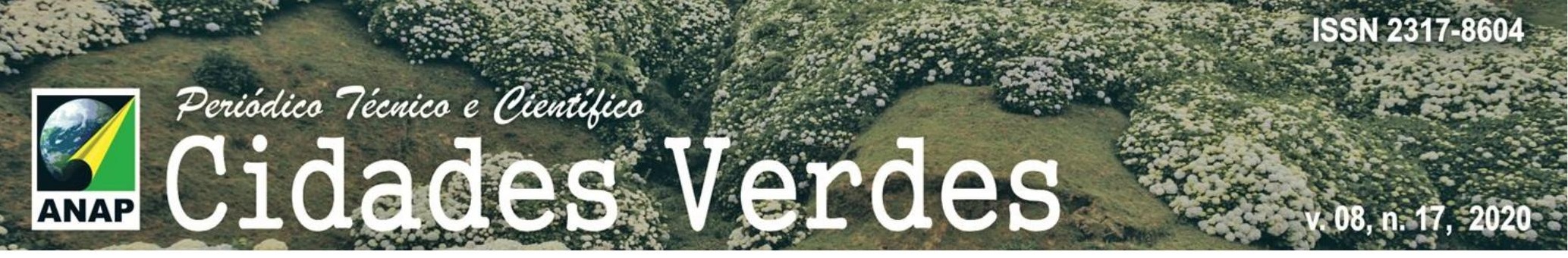

SOUZA, M.A.C. Estudo de perovisquita baseada em titânio para a aplicação em fotocatálise

heterogênea. Dissertação de Mestrado em Engenharia Química pela Universidade Estadual de Ponta Grossa, UEPG, Ponta Grossa, Paraná, 2019.

SOUZA, M.A.C. Substituição da antraquinona por surfactante na polpação. Monografia de Conclusão de Curso em Engenharia Química pela FATEB, Telêmaco Borba, Paraná, 2014. 